\title{
Prejudice Reduction in Public Schools: A Dialogic Approach
}

\author{
Maru Gonzalez \\ North Carolina State University \\ Michael J. Kokozos \\ Gulliver School, Pinecrest, Florida
}

Increasingly, students are facing hostility and violence as a result of one or more of their social group memberships. Such prejudicial attitudes and actions contribute to antagonistic intergroup relationships in public schools (i.e., $\mathrm{K}-12$ ). This article examines dialogic approaches to prejudice reduction, with a specific emphasis on intergroup dialogue in public K-12 schools. Evidence-based steps and strategies that educators can use to develop intergroup dialogue competencies and cultivate a more dialogic environment in their schools and classrooms are also introduced.

Keywords: dialogue, intergroup dialogue, prejudice reduction, school, students

\section{Introduction}

Increasingly, students are experiencing an antagonistic or even violent school climate attributed to one or more of their social identities (Dessel, 2010; Kosciw, Greytak, Zongrone, Clark, \& Truong, 2018; Voight, Hanson, O’Malley, \& Adekanyne, 2015). For example, 2017 data from the Federal Bureau of Investigation's (2018) Hate Crime Statistics revealed a 25\% increase in school-based hate crimes for the second consecutive year. Amidst this backdrop of hostility, and despite well-meaning attempts to embrace multiculturalism and "celebrate diversity," many of the nation's educators lack the tools to effectively and proactively address incidences of bullying and harassment in their schools and classrooms (Gonzalez, 2016, 2017; Kosciw et al., 2018). Such prejudicial attitudes coupled with ineffective or incomplete school-based responses to bias contribute to hostile intergroup relationships in public schools (i.e., $\mathrm{K}-12$ ). To foster a culture of respect and mutual understanding among educators and students, issues of prejudice should be addressed proactively and at the systemic level (Gonzalez, 2017).

To that end, a rich body of literature on attitude formation and change has provided a theoretical framework for prejudice reduction (Crisp, 2005; Pettigrew, 1998; Rutland \& Killen, 2015) and can be applied for use in public schools. Intergroup dialogue (IGD) - a pedagogical approach that seeks to establish common understanding among people whose social identities and life experiences differ from one another (Ford, 2018; Zúñiga, Nagda, Chesler, \& Cytron-Walker, 2007)—is among the various methods used to attend to the issue of prejudice between social identity groups in a variety of settings, including public schools. Although there is ample scholarship regarding IGD in higher education and community settings (Lopez-Humphreys \& Dawson, 2014; Zúñiga et al., 2007), and emerging research as to the ways in which IGD can be applied as a means to promote social justice (Ford, 2018; Hammack, Nagda, Gurin, \& Rodríguez, 2018; Lopez-Humphreys \& Dawson, 2014), limited scholarship exists on IGD in K-12 institutions (Dessel, 2010; Griffin, Brown, \& Warren, 2012). Even the most recent analysis and evaluation of IGD research from 2006 to 2017 had little to offer in regards to "IGD outcomes, processes, and facilitation" within primary and secondary school settings (Frantell, Miles, \& Ruwe, 2019, p. 1). 
This article explores IGD as an effective pathway for prejudice reduction in public schools. The article first explores the concept of prejudice and examines models for prejudice reduction commonly employed in K-12 institutions. Next, the authors look more closely at IGD and prejudice reduction in general and within public schools. Finally, the article investigates some of the potential challenges for facilitators and participants of IGD in public schools and explores strategies for reducing prejudice by engendering IGD competencies in schools and classrooms.

\section{Intergroup Dialogue as a Method to Reduce Prejudice in K-12 Schools}

Most frequently, prejudice is defined as a "negative attitude" (Dovidio et al., 2004, p. 246), generally conceptualized as being unsubstantiated by reason. Multidimensional in scope, prejudice is thought of as encompassing three components: (a) thoughts or beliefs about the attitude object (i.e., cognitive component), (b) feelings and emotions about the attitude object (i.e., affective component), and (c) associations with an individual's previous experiences or projected action toward the attitude object (i.e., behavioral component; Dovidio et al., 2004, p. 246). To effectively reduce prejudice toward the attitude object, all three components must be addressed (Dessel, 2010).

Anchored in humanistic philosophy, humanistic psychology, and social psychology, prejudice reduction models seek to foster mutual understanding across differences. According to Dovidio et al. (2004), there are four types of training and program models aimed at reducing intergroup prejudice: multicultural education, IGD, cooperative learning, and moral and values education. These models are categorized under either an enlightenment or an intergroup contact approach (Dovidio et al., 2004). Broadly speaking, enlightenment approaches leverage cognitive and affective mechanisms to increase sensitivity and extend individuals' knowledge of another group (Dovidio et al., 2004). Conversely, intergroup contact places more of an emphasis on the interaction between members of different social identity groups.

Of the two approaches outlined by Dovidio et al. (2004), IGD is more heavily influenced by intergroup contact, the premise of which is rooted in Gordon Allport's (1954) contact hypothesis. Since its introduction over 60 years ago, Allport's contact hypothesis has proven to be an effective strategy in reducing prejudice (Dovidio et al., 2004). Intergroup contact theory posits that increased contact between groups leads to decreased prejudice, especially if the contact is inherently personal and intimate (Patchen, 1999). A meta-analysis of hundreds of studies on intergroup contact conducted by Pettigrew and Tropp (2008) revealed that more frequent intergroup contact is generally related to decreased levels of intergroup prejudice. Analogous to IGD, certain criteria must be met in order for intergroup contact to successfully reduce prejudice: "equal status between groups; cooperative (rather than competitive) intergroup interaction; opportunities for personal acquaintance between the members... and supportive norms by authorities within and outside the contact situation" (Dovidio et al., 2004, p. 258). Consistent with intergroup contact theory, IGD seeks to foster positive interactions across social identity groups and has been effectively employed to reduce prejudice in a variety of settings, including public schools.

\section{Intergroup Dialogue}

IGD takes different shapes; shared among the various approaches, however, is the goal of providing the space necessary to exchange varying perspectives while seeking mutual understanding (Zúniga, Lopez, \& Ford, 2016). The process of IGD is structured, often consisting of the following features: (a) sustained participation over a period of several weeks, (b) equal status between or among social identity groups, (c) teams of two trained cofacilitators, (d) a focus on critical inquiry and active listening, and (e) an emphasis on engaging in collective social action (Khuri, 2004; Nagda \& Gurin, 2007). The overarching goals of IGD include developing a critical understanding of privilege and oppression, strengthening relationships and understanding across differences, and promoting 
individual and collective action for social change (Zúñiga et al., 2007). Within educational contexts, IGD generally begins with an introduction to content regarding guidelines for effective dialogue followed by a discussion about issues of collective identity. Afterward, participants review specific issues of disagreement or controversy within an individual or systemic context. During the final stages of dialogue, participants are encouraged to participate in coalition building across identity groups and engage in social change initiatives such as advocating for policy change, attending a protest, or creating awareness about social justice issues (Ford, 2018; Hammack et al., 2018; LopezHumphreys \& Dawson, 2014).

Research demonstrates that participation in IGD can motivate attitude change and improve relationships across social identity groups (Aldana, Richards-Schuster, \& Checkoway, 2016; Ford, 2018; Hammack et al., 2018). With regard to prejudice reduction, IGD has been instrumental in enabling empathy and critical self-reflection, two central components for attitude change (Dessel, 2010; Muller \& Miles, 2017). Among youth, participation in IGD has proven effective in fostering a more critical understanding of social justice and social change, driving civic engagement, and nurturing cross-cultural communication (Aldana, Rowley, Checkoway, \& Richards-Schuster, 2012; Ford, 2018; Frantell et al., 2019; Hammack et al., 2018; Lopez \& Nastasi, 2012). IGD has also been employed in higher education classrooms to examine issues related to identity, oppression, and social justice (Lopez-Humphreys \& Dawson, 2014).

\section{Using Dialogue to Reduce Prejudice in K-12 Schools}

Although IGD is more frequently implemented in higher education and community youth settings, there is a growing body of research on the impact of IGD and pedagogy in secondary schools (Griffin et al., 2012; Nagda, McCoy, Barrett, 2006; Tauriac, Kim, Lambe Sariñana, Tawa, \& Kahn, 2013). One initiative being employed is the Study Center's Resource Circle's Resource Center's Mix It Up campaign, a project designed to improve intergroup relations, develop civic skills, and motivate social action (Nagda et al., 2006). The campaign consists of three options: sustained IGDs, which includes identity exploration; cross-cultural communication; and social change. Nagda et al. (2006) conducted a pilot study of the Mix It Up dialogues in which both students and educators were assessed. The dialogues included four sessions and ended with action planning. Survey results revealed that students showed increased knowledge of social boundaries and social climate within their school. Additionally, students agreed that the dialogues "helped them get to know the students in their classes, become more aware of how cliques are helpful and hurtful in school, and understand their role in breaking down social boundaries" (Nagda et al., 2006, p. 52). In spite of the campaign's documented benefits, time constraints limited many schools from full participation in the campaign. Lack of resources also posed an issue. Combined, these factors resulted in incomplete evaluations of the dialogues and revealed areas in need of improvement, including increasing the accessibility of program materials for teachers and providing assistance with organizing the program and training student facilitators. Overall, the results indicated that, when executed properly, Mix It Up dialogues have the potential to reduce prejudice and pave the way for systemic change (Nagda et al., 2006).

A mixed-methods study evaluated the impact of an IGD afterschool program (Griffin et al., 2012). The project, Intergroup Social Change Agents, is a collaboration between the University of Michigan's School of Social Work and four public secondary schools with varying demographic populations. The program-which consists of weekly meetings over a 20 -week span and two all-day interschool exchanges - focuses on identity exploration, conflict resolution, nurturing relationships, and social action (Garvin, 2008). At the end of the program, students from all four participating schools work together on a collaborative social change initiative aimed at improving intergroup relations within their schools and communities. Like the Mix It Up dialogues (Nagda et al., 2006), survey data showed that participation in the program led to an increase in critical social awareness and the development of friendships across social identity groups. Unlike results from the Mix It Up 
dialogues, students in the Intergroup Social Change Agents program (Griffin et al., 2012) reported being more likely to challenge stereotypes and discriminatory behavior as a result of their participation.

Another study related to IGD among high school students involved a university collaboration with two local high schools (Lopez \& Nastasi, 2012). Consistent with previous findings on IGD, student responses to an open-ended survey revealed that participation in the program led to a greater awareness of inequality, reflections of their own capacity to create change, and a desire for additional engagement. A study of an intergroup relations project at two high schools by Spencer, Brown, Griffin, and Abdullah (2008) yielded similar results. The program, which used intergroup pedagogy to reduce intergroup conflict, had a positive impact on students. Specifically, findings indicated more profound social awareness among participants, improved intergroup relations and conflict resolution skills, and a decrease in prejudicial attitudes toward members of different social identity groups. These results reflect those of an IGD study conducted with 64 racially diverse secondary students at a progressive, independent high school (Tauriac et al., 2013). Student feedback, including from surveys and meetings immediately after and 6 weeks following participation in the IGD program, yielded positive results. Systemically, students stated that the IGD workshop motivated several efforts to improve the racial climate at school, including biweekly student and faculty forums related to race and racism on campus. At the individual level, several students expressed an interest in developing interracial friendships and participating in student organizations related to diversity. Overall, participation in the IGD workshop led to improved interracial relations, greater social awareness of intergroup dynamics, and a desire to engage in systemic change related to racial climate on campus.

IGD in K-12 schools is not solely limited to students and can be used to reduce prejudicial attitudes and behaviors among faculty and staff. A mixed-methods study conducted by Dessel (2010) tested the impact of IGD on public school teacher attitudes, behaviors, and feelings about lesbian, gay, and bisexual students and parents. Findings revealed that dialogue participation resulted in positive changes in attitudes, behaviors, and feelings toward lesbian, gay, and bisexual students and parents. Revisiting the study conducted by Nagda et al. (2006) revealed information regarding educators' perceptions of school climate and the impact of the Mix It Up dialogues on students. Although educators (i.e., teachers, counselors, and administrators) did not take part in the dialogues, they participated in either a survey questionnaire or a qualitative interview. Data showed that $85 \%$ of teachers and administrators expressed concern regarding school climate. Results also indicated that administrator support facilitates dialogue success. Overall, educators indicated that the dialogues had a positive impact on both students and the school environment.

These studies demonstrated that when provided with adequate time, resources, and a supportive administration, IGD in public schools can yield positive results. Consistent with IGD research conducted in other settings (Aldana et al., 2016; Lopez \& Nastasi, 2012), implementation of IGD in public schools-whether with students or faculty and staff-results in increased social awareness and prejudice reduction.

\section{Challenges of IGD in public schools}

In spite of its well-documented benefits, IGD in public schools poses several challenges. Bringing students together to talk about issues of social oppression is by no means an easy feat. Such issues are often the source of controversy, which administrators would rather avoid. And as with most sustained dialogues, the question of time is often a barrier. Within school settings, many teachers are reluctant to allow students to miss class time, as was the case with the Mix It Up dialogues (Nagda et al., 2006). Acquiring the money to fund dialogues and train facilitators is another obstacle. 
Yet despite its challenges, IGD "has the potential to become a living laboratory... [where] young people can engage with their peers and with adults in the art of democracy" (p. 55).

\section{Strategies for Fostering IGD Competencies in Schools}

While IGD has proven effective as a model of prejudice reduction in higher education and community youth settings, additional research is needed to further explore the promise of IGD in K-12 institutions. Further, given the barriers often associated with its implementation, IGD may not be a viable option for all public school educators. Nevertheless, there exist evidence-based steps and strategies for teaching IGD competencies and cultivating more dialogic-and therefore less biasedschools and classrooms. Informed by the literature review and guided by the core goals of IGD (Zúniga et al., 2007), the following are dialogic strategies that may aid in reducing prejudice in public schools.

\section{Cultivate Connected Learning Communities}

Establishing trust is an essential first step in cultivating a culture of connection and understanding across differences. To build trust, students and educators must work together to engender a dialogic space where empathy, understanding, and compassion thrive. Wasserman and Doran (1999) referred to such a space as a learning community, which they describe as "... a safe yet challenging environment composed of people who support each other as they explore their differences" (p. 307). Anchored in the six building blocks of dialogue, a learning community provides the support and affirmation necessary for people to "speak their voice" in a way that feels safe, which is foundational to IGD. Moreover, the principles of a learning community very much reflect the six building blocks. These include being fully present, listening actively and intently, taking risks and honoring boundaries (pp. 308-309). Creating community agreements at the beginning of a new school year or before an emotionally charged lesson is one way students can express what they need to feel comfortable speaking authentically in the classroom (Zúñiga, et al., 2016). Related to this awareness of students' needs is a focus on universal curriculum design, one that considers varying needs and learning styles, as well as the ways in which identity, culture, and experiences shape the educational lens of each student.

\section{Practice Voicing, Active Listening, Inquiry, and Self-Reflection}

Once trust has been established, opening one's self up in a group setting can be a powerful experience. It allows students to connect with others on a deeper level and find the common threads that exist in all human stories. Within IGD, such authentic sharing can be described as a form of voicing, one of dialogue's six essential building blocks (Ellinor \& Gerard, 1998). In dialogue scholarship, voicing is described as "revealing what is true for you regardless of other influences that might be brought to bear" (Isaacs, 1999, p. 159). Much in the same vein, inquiry, active listening, and reflection help shape the structure of dialogue and set the foundation for meaningful exchange. Ellinor \& Gerard (1998) described inquiry as "asking questions, opening the door for new insights" (p. 111) and reflection as "holding the door long enough for new perceptions to emerge" (p. 111). In this sense, the two concepts are very much connected; that is, inquiry necessitates reflection while reflection generates a more intentional and authentic level of inquiry. Combined, they allow students to explore complex issues-including and especially those related to oppression and social identityat a more profound level. Within the classroom, there are numerous strategies educators can employ to promote voicing, active listening, inquiry, and self-reflection, including think-pair-share and fishbowls exercises, journaling, and the sharing of personal narratives. The latter, in particular, “... creates bonds, increases listening skills, and fosters communication" (De Vos, Harris, \& Lottridge, 2003, p. 3). 


\section{Raise Consciousness}

Within the context of IGD, raising consciousness refers to creating awareness and critical understanding of the dynamics of power, socialization, and social inequality across social identity groups (Aldana et al., 2012; Frantell et al., 2019). Integrating the stories and experiences of marginalized populations into the curriculum can further aid in disrupting dominant and misguided narratives about said populations (Rodriguez, 2010), thereby reducing prejudicial attitudes and behaviors. In terms of resources, numerous blogs and websites provide engaging yet diverse perspectives of the most critical social issues of our time. A prominent example is the website https://www.HumansofNewYork.com/, which can be navigated based on country or topic, from the plight of refugees to children battling pediatric cancer. For marginalized students, in particular, listening to the voices of those whose stories are often silenced and misrepresented can serve as a "bicultural mirror, validating, supporting, and encouraging students during cognitive disequilibrium" (Rodriguez, 2010, p. 498). Moreover, such stories provide insights into structural oppression, shedding light on the need to invoke societal change, thereby empowering both the narrator and listener (Delgado, 1989). The personal sharing of stories-whether digital, oral, or through photographs-is another effective method for raising consciousness and cultivating connection across differences (Anderson \& Mack, 2019; Beucher, 2016).

\section{Nurture Youth Leadership}

One of the core aims of IGD is to move from critical awareness and cross-cultural communication skills to individual and collective social action (Dessel \& Rodenborg, 2017; Khuri, 2004; Nagda \& Gurin, 2007). For social change to be effective in the classroom, it is first necessary to establish a dialogic classroom by adhering to the strategies outlined above and nurturing students' capacity for transformation. Educators guide this process by conducting a needs assessment, identifying strategic alliances, and developing informed action plans in collaboration with students. Whenever possible, this process necessitates moments of celebration - the celebration of hard work and the celebration of resilience, among others. A research methodology emblematic of these applied techniques-Youth Participatory Action Research-has shown promise as a means of nurturing youth leadership within the framework of IGD (Aldana et al. 2016). Key tenets of this approach include involving students in both the execution of the project and its knowledge production as a means to foster positive social change (Mirra, Garcia, \& Morrell, 2016).

\section{Build Capacity Among Faculty and Staff}

School personnel are seldom trained to respond to bias between or among students; therefore, they tend to lack the knowledge and skills necessary to effectively intervene when such incidences occur (Griffin et al., 2012; Kosciw et al., 2018). Proactive and systemic responses to prejudice are even less likely to be included as part of standard teacher and school counselor education and training (Gonzalez, 2017). If prejudice reduction methods in schools are to be effective-whether dialogic or otherwise—capacity building among faculty and staff must be included in prejudice reduction efforts. Integrating dialogic techniques-including active listening, communication across differences, selfreflection, and systemic change-will further aid in cultivating a more dialogic and inclusive school climate and culture.

\section{Conclusion}

In an effort to engender a climate of respect, educators often employ measures aimed at reducing bias and increasing mutual understanding of differences. While well intentioned, many of these strategies (e.g., organizing an assembly or a day of action) tend to be misguided, short-term solutions and occur at the individual level, thereby limiting the potential for sustainable change. IGD offers a 
different approach, one that seeks to cultivate a culture of respect and mutual understanding while challenging dominant narratives of socialization (Dessel, 2010; Zúniga et al., 2007). Indeed, participation in IGD provides an opportunity for students to engage with one another across social group boundaries in a manner that engenders collective inquiry, self- and collective reflection, and motivates collective action (Aldana et al., 2016; Griffin et al., 2012; Nagda et al., 2006).

The success of programs aimed at improving intergroup relations is contingent upon various factors including the skill of the practitioner(s), the receptiveness of participants, and the clarity and specificity of outcomes (Dovidio et al., 2004). Based on these factors-as well as the results of a needs assessment-faculty, staff, and students can determine which programs or strategies are best suited to address the issues at hand. As Dovidio et al. posited, "it is not sufficient to have a 'good' program; it is equally important to have an 'appropriate' program" (p. 264). With its focus on seeking common ground, listening, and social change, IGD is both a "good" and appropriate method for reducing prejudice in $\mathrm{K}-12$ institutions.

\section{References}

Aldana, A., Rowley, S. J., Checkoway, B., \& Richards-Schuster, K. (2012). Raising ethnic-racial consciousness: The relationship between intergroup dialogues and adolescents' ethnic-racial identity and racism awareness. Equity \& Excellence in Education, 45, 120-137. doi:10.1080/10665684.2012.641863

Aldana, A., Richards-Schuster, K., \& Checkoway, B. (2016). Dialogic pedagogy for youth participatory action research: Facilitation of an intergroup empowerment program. Social Work with Groups, 39, 339-358.

Allport, G. W. (1954). The nature of prejudice. Cambridge, MA: Addison-Wesley.

Anderson, K. M., \& Mack, R. (2019). Digital storytelling: A narrative method for positive identity development in minority youth. Social Work with Groups, 42, 43-55. doi:10.1080/01609513.2017.1413616

Beucher, R. (2016). Speaking through digital storytelling: A case study of agency and the politics of identity formation in school. In S. Greene, K. Burke, \& M. McKenna (Eds.), Youth voices, public spaces, and civic engagement (pp. 50-67). New York, NY: Routledge.

Crisp, R. J. (2005). Reducing intergroup bias: The moderating role of ingroup identification. Group Processes \& Intergroup Relations, 8, 173-185. doi:10.1177/1368430205051066

Delgado, R. (1989). Storytelling for oppositionists and others: A plea for narrative. Michigan Law Review, 87, 2411-2441.

Dessel, A. B. (2010). Effects of intergroup dialogue: Public school teachers and sexual orientation prejudice. Small Group Research, 41, 556-592. doi:10.1177/1046496410369560

Dessel, A. B., \& Rodenborg, N. (2017). An evaluation of intergroup dialogue pedagogy: Addressing segregation and developing cultural competency. Journal of Social Work Education, 53, 222239. doi:10.1080/10437797.2016.1246269

De Vos, G., Harris, M., \& Lottridge, C. B. (2003). Telling tales: Storytelling in the family. Edmonton, Canada: University of Alberta Press.

Dovidio, J. F., Gaertner, S. L., Stewart, T. L., Esses, V. M., ten Vergert, M., \& Hodson, G. (2004). From intervention to outcome: Processes in the reduction of bias. In W. G. Stephan \& W. P. Vogt (Eds.), Education programs for improving intergroup relations: Theory, research, and practice (pp. 243-265). New York, NY: Teachers College Press. 
Ellinor, L., \& Gerard, G. (1998). Dialogue: Rediscovering the transforming power of conversation. New York, NY: John Wiley \& Sons.

Federal Bureau of Investigation. (2018). 2017 Hate crimes statistics. Retrieved from https://ucr.fbi.gov/hate-crime/2017

Ford, K. A. (2018). Facilitating change through intergroup dialogue: Social justice advocacy in practice. New York, NY: Routledge.

Frantell, K. A., Miles, J. R., \& Ruwe, A. M. (2019). Intergroup dialogue: A review of recent empirical research and its implications for research and practice. Small Group Research, 50, 654695. doi:10.1177/1046496419835923

Gonzalez, M. (2016). Factors that facilitate and impede advocacy for and with LGBT students. Journal of Counselor Leadership and Advocacy, 3, 158-172.

Gonzalez, M. (2017). Advocacy for and with LGBT students: An examination of high school counselor experiences. Professional School Counseling, 20, 38-46.

Griffin, S. R., Brown, M., \& Warren, N. M. (2012). Critical education in high schools: The promise and challenges of intergroup dialogue. Equity and Excellence in Education, 45, 159-180. doi:10.1080/10665684.2012.641868

Hammack, P., Nagda, B., Gurin, P., \& Rodríguez, J. (2018). Intergroup dialogue: Education for social justice. In P. Hammack (Ed.), The Oxford handbook of social psychology and social justice (pp. 379-402). Oxford, United Kingdom: Oxford University Press.

Isaacs, W. (1999). Dialogue and the art of thinking together. New York, NY: Doubleday.

Khuri, M. L. (2004). Working with emotion in educational intergroup dialogue. International Journal of Intercultural Relations, 28, 595-612. doi:10.1016/j.ijintrel.2005.01.012

Kosciw, J. G., Greytak, E. A., Zongrone, A., Clark. C. M., \& Truong, N. L. (2018). The 2017 national school climate Survey: The experiences of lesbian, gay, bisexual, and transgender youth in our nation's schools. New York, NY: Gay, Lesbian, and Straight Education Network.

Lopez, G. E., \& Nastasi, A. W. (2012). Writing the divide: High school students crossing urbansuburban contexts. Equity \& Excellence in Education, 45, 138-158.

Lopez-Humphreys, M., \& Dawson, B. A. (2014). From education to action: The immediate and longterm results of intergroup dialogue on BSW students' social justice activity. Journal of Baccalaureate Social Work, 19, 31-43. doi:10.1080/10665684.2012.643676

Mirra, N., Garcia, A., \& Morrell, E. (2016). Doing youth participatory action research: Transforming inquiry with researchers, educators, and students. New York, NY: Routledge.

Muller, J. T., \& Miles, J. R. (2017). Intergroup dialogue in undergraduate multicultural psychology education: Group climate development and outcomes. Journal of Diversity in Higher Education, 10, 52-71. doi:10.1037/a0040042

Nagda, B., \& Gurin, P. (2007). Intergroup dialogue: A critical-dialogic approach to learning about difference, inequality, and social justice. New Directions for Teaching and Learning, 111, 35-45. doi:10.1002/tl.284

Nagda, B., McCoy, M., \& Barrett, M. (2006). Mix it up: Crossing social boundaries as a pathway to youth civic engagement. National Civic Review, 95, 47-56.

Patchen, M. (1999). Diversity and unity: Relations between racial and ethnic groups. Chicago, IL: Nelson-Hall.

Pettigrew, T. F. (1998). Intergroup contact theory. Annual Reviews of Psychology, 49, 65-85. 
Pettigrew, T. F., \& Tropp, L. R. (2008). How does intergroup contact reduce prejudice? Meta-analytic tests of three mediators. European Journal of Social Psychology, 38, 922-934. doi:10.1002/ejsp.504

Rodriguez, D. (2010). Storytelling in the field: Race, method, and the empowerment of Latina college students. Cultural Studies Critical Methodologies, 10, 491-507.

Rutland, A., \& Killen, M. (2015). A developmental science approach to reducing prejudice and social exclusion: Intergroup processes, social-cognitive development, and moral reasoning. Social Issues and Policy Review, 9, 121-154. doi:10.1111/sipr.1201210.1111/sipr.120122015-00569-005

Spencer, M. S., Brown, M., Griffin, S., \& Abdullah, S. (2008). Outcome evaluation of the intergroup project. Small Group Research, 39, 82-103.

Tauriac, J. J., Kim, G. S., Lambe Sariñana, S. A., Tawa, J., \& Kahn, V. (2013). Utilizing affinity groups to enhance intergroup dialogue workshops for racially and ethnically diverse students. The Journal for Specialists in Group Work, 38, 241-260. doi:10.1080/01933922.2013.800176.

Voight, A., Hanson, T., O’Malley, M., \& Adekanyne, L. (2015). The racial school climate gap: With-in school disparities in students' experiences of safety, support, and connectedness. American Journal of Community Psychology, 56, 252-267. doi:10.1007/s10464-015-9751-x

Wasserman, I., \& Doran, R. (1999). Creating inclusive learning communities. In A. Cooke, M. Brazzel, A. Craig, \& B. Greig (Eds), Reading book for human relations training (pp. 307310). Arlington, VA: NTL Institute.

Zúñiga, X., Lopez, G., \& Ford, K. A. (2016). Intergroup dialogue: Engaging difference, social identities and social justice. New York, NY: Routledge.

Zúñiga, X., Nagda, B. A., Chesler, M., \& Cytron-Walker, A. (2007). Intergroup dialogues in higher education: Meaningful learning about social justice (ASHE Higher Education report series 32). San Francisco, CA: Jossey-Bass.

The Journal of Educational Research and Practice provides a forum for studies and dialogue that allows readers to better develop social change in the field of education and learning. Journal content may focus on educational issues of all ages and in all settings. It also presents peer-reviewed commentaries, book reviews, interviews of prominent individuals, and additional content. The objectives: We publish research and related content that examines current relevant educational issues and processes aimed at presenting readers with knowledge and showing how that knowledge can be used to impact social change in educational or learning environments. Additional content provides an opportunity for scholarly and professional dialogue regarding that content's usefulness in expanding the body of scholarly knowledge and increasing readers' effectiveness as educators. The journal also focuses on facilitating the activities of both researcher-practitioners and practitioner-researchers, providing optimal opportunities for interdisciplinary and collaborative thought through blogging and other communications. Walden University Publishing: http://www.publishing.waldenu.edu 